\title{
Letter to the Editor on "Treatment Adherence and Clinical Outcomes of Patients with Inflammatory Bowel Disease Patients During the SARS-CoV-2 Pandemic"
}

\author{
Cong Dai ${ }^{1}\left[\right.$ Pu-hong Huang ${ }^{1}$
}

Received: 25 January 2021 / Accepted: 12 March 2021 / Published online: 29 April 2021

(c) The Author(s), under exclusive licence to Springer Science+Business Media, LLC, part of Springer Nature 2021

To the Editors

We read with interest the article by Iborra et al. [1] describing the clinical outcomes and the fulfillment of the treatment schedule of patients with IBD treated with biological agents at their unit. They found that adherence to intravenous and subcutaneous biological therapies during the pandemic was high in a single-center cohort of patients with IBD even though the cumulative incidence of confirmed COVID-19 was low. But we have reached different conclusions via a questionnaire including the disease activity and treatment schedules of patients with IBD at our unit during the COVID-19 pandemic.

A total of 239 patients ( 71 patients with CD, 151 patients with UC and 17 patients with unclassified IBD) participated in the questionnaire, including 108 (45.2\%) women and 131 (54.8\%) men (Table 1). Median age of patients with IBD was 41 years old. During the COVID-19 pandemic, 188 (78.7\%) patients reported that their disease was in clinical remission period based on clinical symptoms, and 51 (21.3\%) patients had fever, abdominal pain, diarrhea, hematochezia, vomiting, joint pain. Our results showed that the COVID-19 pandemic delayed IBD-related examinations and operations. And 128 (53.6\%) patients reported that the examinations including biochemical tests, colonoscopy, abdominal CT were delayed. In addition, $13(5.4 \%)$ patients delayed surgical treatment. In all, $43.8 \%$ of patients chose the Internet platform for medical consultation. Mobile communication such as Wechat accounted for $57.5 \%$ of online medical consultation during the COVID-19 pandemic. The results of our study showed that there were significant differences in medical consultation and the method of buying drugs before and after the COVID-19 pandemic.

At the same time, 52 (21.8\%) patients (14 patients with $\mathrm{CD}, 32$ patients with UC and 6 patients with unclassified IBD) have changed their treatment schedules. Before the COVID-19 pandemic, $53.4 \%$ of patients used 5-ASA, 3.7\% used corticosteroids, $12.7 \%$ used immunosuppressive drugs, and $14.2 \%$ used biological agents (Infliximab and Adalimumab). However, $21.8 \%$ of patients changed their treatment schedules, 55.3\% used 5-ASA, $2.0 \%$ used corticosteroids, $11.5 \%$ used immunosuppressive drugs, and $14.2 \%$ used biological agents during the COVID-19 pandemic. And $31.1 \%$ of patients who changed their treatment schedules complained that they could not buy enough drugs or use infliximab on time. The main reason was that many hospitals were unable to open and treat non-COVID-19 patients in the COVID-19 pandemic. Therefore, 41 (17.2\%) patients had delayed the use of infliximab, and $36(87.8 \%)$ patients had delayed for more than two weeks. Most of these patients (70.5\%) had to stop using biological agents.

In conclusion, we found that the COVID-19 has significantly affected the treatment schedule and medical consultation of patients with IBD treated with biological agents at our unit.

Author's contribution Cong Dai wrote the paper. Cong Dai and Yuhong Huang had the original idea for the paper. All authors reviewed and approved the final draft of the paper.
Cong Dai

congdai2006@sohu.com

1 Department of Gastroenterology, First Affiliated Hospital, China Medical University, No. 92 of Beier Road,

Heping District, Shenyang City 110001, Liaoning Province, China 
Table 1 Demographic and clinical features of IBD patients

\begin{tabular}{|c|c|c|}
\hline & $\begin{array}{l}\text { Unchanged } \\
\text { treatment } \\
\text { schedule }\end{array}$ & $\begin{array}{l}\text { Changed } \\
\text { treatment } \\
\text { schedule }\end{array}$ \\
\hline Patients & $187(78.24 \%)$ & $52(21.76 \%)$ \\
\hline \multicolumn{3}{|l|}{ Gender } \\
\hline Male & $100(53.48 \%)$ & $31(59.62 \%)$ \\
\hline Female & $87(46.52 \%)$ & $21(40.38 \%)$ \\
\hline \multicolumn{3}{|l|}{ Disease } \\
\hline $\mathrm{CD}$ & $57(30.48 \%)$ & $14(26.92 \%)$ \\
\hline $\mathrm{UC}$ & $119(63.64 \%)$ & $32(61.54 \%)$ \\
\hline Unclassified & $11(5.88 \%)$ & $6(11.54 \%)$ \\
\hline \multicolumn{3}{|l|}{ Age } \\
\hline$\leq 16$ & $3(1.60 \%)$ & $0(0 \%)$ \\
\hline $16 \sim 40(>16, \leq 40)$ & $82(43.85 \%)$ & $32(61.54 \%)$ \\
\hline $40 \sim 65(>40, \leq 65)$ & $90(48.13 \%)$ & $20(38.46 \%)$ \\
\hline$>65$ & $12(6.42 \%)$ & $0(0 \%)$ \\
\hline \multicolumn{3}{|l|}{ Time of the last treatment in hospital } \\
\hline$\leq 3$ months & $50(26.74 \%)$ & $20(38.46 \%)$ \\
\hline $\begin{array}{l}3 \sim 6 \text { months } \\
\text { (>3 months, } \leq 6 \text { months })\end{array}$ & $43(22.99 \%)$ & $13(25 \%)$ \\
\hline $\begin{array}{l}6 \sim 12 \text { months } \\
\quad(>6 \text { months }, \leq 12 \text { months })\end{array}$ & $44(23.53 \%)$ & $11(21.15 \%)$ \\
\hline$>12$ months & $50(26.74 \%)$ & $8(15.38 \%)$ \\
\hline \multicolumn{3}{|l|}{ Course of disease } \\
\hline$\leq 2$ years & $99(52.94 \%)$ & $30(57.69 \%)$ \\
\hline $2 \sim 5$ years $(>2$ years, $\leq 5$ years $)$ & $46(24.60 \%)$ & $10(19.23 \%)$ \\
\hline $5 \sim 10$ years $(>5$ years, $\leq 10$ years $)$ & $26(13.90 \%)$ & $8(15.38 \%)$ \\
\hline$>10$ years & $16(8.56 \%)$ & $4(7.69 \%)$ \\
\hline \multicolumn{3}{|l|}{ Before COVID-19 pandemic } \\
\hline 5 -ASA & $132(61.11 \%)$ & $34(53.13 \%)$ \\
\hline Corticosteroid & $7(3.24 \%)$ & $5(7.81 \%)$ \\
\hline Immunosuppressive & $30(13.89 \%)$ & $9(14.06 \%)$ \\
\hline Biologic therapy & $35(16.20 \%)$ & $11(17.19 \%)$ \\
\hline Others & $12(5.56 \%)$ & $5(7.81 \%)$ \\
\hline \multicolumn{3}{|l|}{ After COVID-19 pandemic } \\
\hline 5-ASA & $126(62.07 \%)$ & $33(56.90 \%)$ \\
\hline Corticosteroid & $3(1.48 \%)$ & $3(5.17 \%)$ \\
\hline Immunosuppressive & $27(13.30 \%)$ & $7(12.07 \%)$ \\
\hline Biologic therapy & $31(15.27 \%)$ & $11(18.97 \%)$ \\
\hline Others & $16(7.88 \%)$ & $4(6.90 \%)$ \\
\hline \multicolumn{3}{|l|}{ Disease activity } \\
\hline Remission period & $152(81.28 \%)$ & $36(69.23 \%)$ \\
\hline Relapse period & $35(18.72 \%)$ & $16(30.77 \%)$ \\
\hline \multicolumn{3}{|c|}{ Whether delay the use of biological agents } \\
\hline Unused & $139(74.33 \%)$ & $34(65.38 \%)$ \\
\hline No & $19(10.16 \%)$ & $6(11.54 \%)$ \\
\hline Yes & $29(15.51 \%)$ & $12(23.08 \%)$ \\
\hline
\end{tabular}

\section{Declarations}

Conflict of interest The authors declare that they have no conflict of interests.

\section{References}

1. Iborra I, Puig M, Marin L, Calafat M, Canete F, Quinones C, Gonzalez-Gonzalez L, Cardona G, Manosa M, Domenech E. Treatment adherence and clinical outcomes of patients with inflammatory bowel disease on biological agents during the SARS-CoV-2 pandemic. Dig Dis Sci. 2021. https://doi.org/10. 1007/s10620-020-06807-0.

Publisher's Note Springer Nature remains neutral with regard to jurisdictional claims in published maps and institutional affiliations. 